\title{
Load frequency control of thermal system under deregulated environment using slime mould algorithm
}

\author{
Sambugari Anil Kumar' ${ }^{1}$, M. Siva Sathya Narayana ${ }^{2}$, K. Jithendra Gowd ${ }^{3}$ \\ ${ }^{1}$ Department of Electrical and Electronics Engineering, Jawaharlal Nehru Technological University, Ananthapuramu, \\ Andhra Pradesh, India \\ ${ }^{2}$ Department of Electrical and Electronics Engineering, G. Pulla Reddy Engineering College (Autonomous), Andhra \\ Pradesh, India \\ ${ }^{3}$ Department of Electrical and Electronics Engineering, JNTUA College of Engineering, Ananthapuramu, Andhra \\ Pradesh, India
}

\begin{tabular}{|c|c|}
\hline Article Info & ABSTRACT \\
\hline Article history: & This paper emphasizes the significance of proportional-integral-derivative \\
\hline Received May 14, 2021 & (PID) controller parameters using a slime mould algorithm (SMA) to reduce \\
\hline Revised Sep 22, 2021 & scenario. The SMA is used to solve the parameterization of the PID controller, \\
\hline Accepted Sep 29, 2021 & $\begin{array}{l}\text { which was formulated as an optimization problem. The performance of the PID } \\
\text { controller parameters improves the dynamic characteristics of the system as }\end{array}$ \\
\hline Keywords: & $\begin{array}{l}\text { frequency in each area, and also deviations in tie line power after sudden load } \\
\text { violation. In order to study the efficiency of the proposed method, the system }\end{array}$ \\
\hline Disco participation matrix & was tested with different power transactions for a small load disturbance and \\
\hline Load frequency control & $\begin{array}{l}\text { the comparative results were presented. The optimal value of the controller } \\
\text { parameters derived from SMA based PID controller is estimated using a finite }\end{array}$ \\
\hline PID controller & nonlinear optimization using a performance index based method. \\
\hline
\end{tabular}

This is an open access article under the CC BY-SA license.

\section{Corresponding Author:}

Sambugari Anil Kumar

Department of Electrical and Electronics Engineering

Jawaharlal Nehru Technological University

Ananthapuramu, Andhra Pradesh 515002, India

Email: sanil.0202@gmail.com

\section{INTRODUCTION}

Each plant needs to monitor load fluctuations and ensure high quality power delivery to its customers throughout the day. Therefore, the same power cannot be supplied constanly, and the amount of power generated changes according to load fluctuations. The main purpose of the control scenario is to generate and supply power in such a stable and economical interconnected system, but keep the frequency and voltage of the power supply within significant limits. Since reactive power changes as the voltage changes, the frequency of the system changes primarily due to load disturbances. The main purposes of the LFC are; i) to keep frequency within acceptable range; ii) maintain a balance between power generation and load; iii) to keep the power deviations within the limit.

The vast grid of electrical systems is connected to many areas by connections. Network analysis of reconstructed networks faces the complexity of analysis due to its scaling. Sudden changes in the effect of the load on the system frequency can lead to uncertain and unstable operation. Therefore, plant working to maintain the load frequency variations is one of the major issues for Electrical Engineers. The problem with LFC is controlling the frequency and power bias between the correlation control elements [1], [2]. A very complex task is to ensure that the entire grid of the electrical system is in equilibrium due to the increasing 
energy demand in the current scenario. The load is always different depending on the power system. The main purpose of LFC is to maintain the true energy balance of the electrical system. The frequency of the system is determined by the generator's mechanical input force. The frequency of the system is directly influenced by variations in power. The frequency must be kept within safe limits by the controller. This frequency error is amplified and delivered to the control unit, which then sends it back to the turbine's speed controller and electrical system network, operating according to block and additional reserves after major disturbance [3], [4].

Deregulation of the electricity industry is the restructuring of the rules and profit incentives established by the government to manage and operate the electricity industry. As part of the deregulation, utilities were abolished as a separate entity having power generation companies (GENCO), transport company (TRANSCO), and distribution company (DISCO). In this open market scenario, a central authority called the independent system operator (ISO) governs the spot market participants. In the real-time electricity market, most vertically integrated utility (VIU) ancillary services play various roles in a deregulated environment. The ancillary services should be implemented by ISO in different ways to explain certain problems such as bilateral contracts between controlled areas and policies of deregulation [5]-[10].

Many researchers anticipated various control methods for balancing the LFC problems. A conventional controller used in automatic generation control (AGC) is PID controller due to their simple construction, consistency and ample variety of applications which are explained in [11]-[16]. The nonlinearities like governor dead band (GDB) and generation rate constraint (GRC) also affect the performance of the LFC [17]-[20]. Various soft computing techniques proposed for LFC problems [21]-[27].

\section{MULTI AREA DEREGUATED SYSTEM}

Figure 1 shows the block diagram representation of two area system under deregulation environment. Each area consists of two genco's and two discom's.

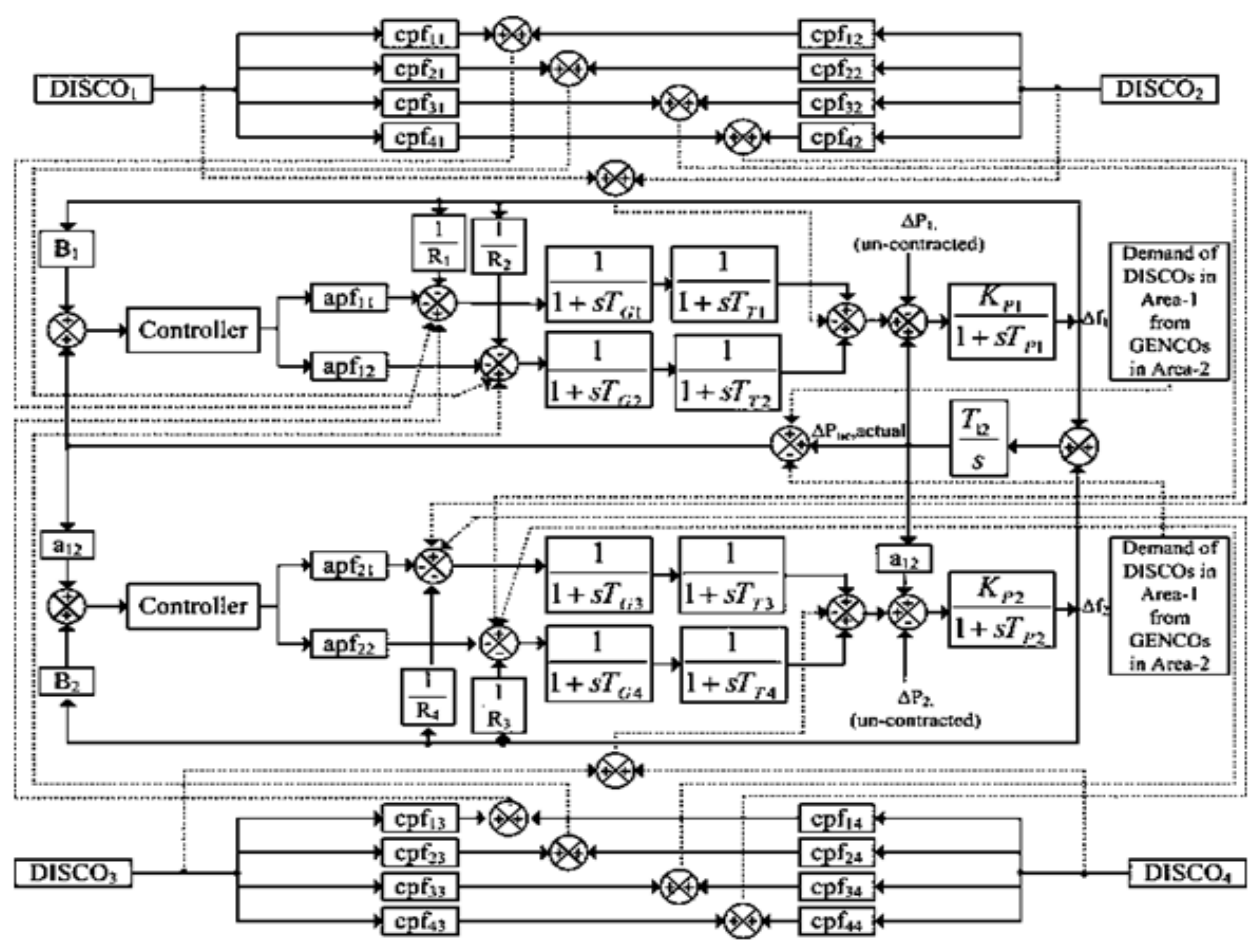

Figure 1. Diagram of two area system under deregulation

\subsection{Traditional electric power system scenario}

The traditional electricity market consists of utilities that own and operate their own electricity. From production to distribution, the public service has full control. Utilities own the infrastructure and power lines and sell them directly to consumers. Utilities must comply with the electricity tariffs set by each state 
utility council. This type of market is often called a monopoly due to limited consumer choice. However, its advantages include stable prices and long-term security.

\subsection{Deregulation power system scenario}

The term deregulation is the process of changing the rules and regulations that govern the electricity sector, allowing consumers to choose their electricity supplier. Free electricity market. This allows market participants to invest in power plants and transmission lines, allowing competitors to buy and sell electricity. Genco owners wholesale this electricity to retailers. Retail outlets set prices for consumers. In many cases, this makes profit for consumers by allowing them to compare prices and services from unlike third party providers and offering a special contract structure.

\subsection{Disco participation matrix}

The AGC system consists of two systems with equal area, i.e., thermal and hydro electric units. In each area there are two gencos and two discos. The coefficient of participation in the contract corresponds to the percentage of the total amount that DISCO $\mathrm{j}$ has concluded with GENCO $\mathrm{i}$. The total number of entries in the column must equal to unity. Disco participation matrix is given by.

$$
D P M=\left[\begin{array}{llll}
c p f_{11} & c p f_{12} & c p f_{13} & c p f_{14} \\
c p f_{21} & c p f_{22} & c p f_{23} & c p f_{24} \\
c p f_{31} & c p f_{32} & c p f_{33} & c p f_{34} \\
c p f_{41} & c p f_{42} & c p f_{43} & c p f_{44}
\end{array}\right]
$$

\section{SLIME MOULD ALGORITHM}

The proposed algorithm (SMA) is a population-based heuristic algorithm proposed by Li et al. in 2020. This algorithm is inspired by the nature of the behavior of mould during oscillation movements. The basic design of this algorithm is shown in Figure 2 which is based on the optimal food path, using both positive and negative feedback systems. The molecule dynamically adjusts the search path to search for food quality. The SMA algorithm follows three main principles: grabble, wrap and approach. Grabble prevents other molecules from colliding during the food fishing process. The grab phenomenon shows the same velocity of viscous forms. The phenomenon of the approach shows that how to move towards the center of food.

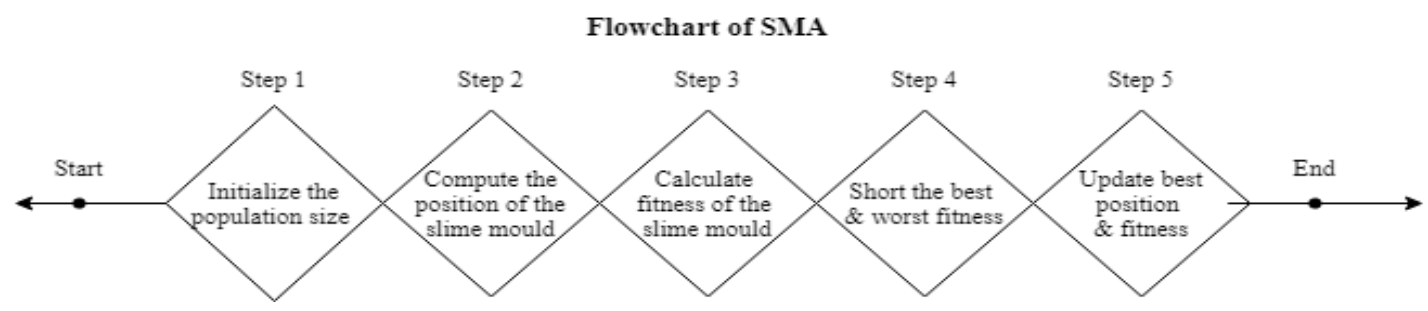

Figure 2. Flowchart of slime mould Algorithm

\subsection{Step: 1 approach food}

The impending behaviour of slime moulds as a mathematical equation to replicate the contraction mode:

$$
\begin{aligned}
& \overrightarrow{X(t+1)}=\left\{\begin{array}{c}
\overrightarrow{X_{b}(t)}+\vec{v}_{b} \cdot\left(\vec{W} \cdot \vec{X}_{A}(t)-\overrightarrow{\left.X_{B}(t)\right)}, r<p\right. \\
\overrightarrow{v_{c}} \cdot \overrightarrow{X(t)}, r \geq p
\end{array}\right. \\
& p=\tanh \mid S(i)-D F \\
& \overrightarrow{v_{b}}=[-a, a] \\
& a=\arctan h\left(-\left(\frac{t}{\text { maxt }_{t}}\right)+1\right)
\end{aligned}
$$

The weight of the slime mould is. 
$\overrightarrow{W(\text { smellIndex }(l))}=\left\{\begin{array}{c}1+r \cdot \log \left(\frac{b F-S(i)}{b F-w F}+1\right), \text { condition } \\ 1-r \cdot \log \left(\frac{b F-S(i)}{b F-w F}+1\right), \text { other }\end{array}\right\}$

Smellindex $=\operatorname{sort}(S)$

\subsection{Step: 2 wrap foods}

The equation for updating the position of the slime mould is:

$$
\overrightarrow{\dot{X}}=\left\{\begin{array}{c}
\text { rand }(U B-L B)+L B, \text { rand }<z \\
\overrightarrow{X_{b}(t)}+\overrightarrow{X_{b}(t)} \cdot\left(W \cdot \overrightarrow{X_{A}(t)}-\overrightarrow{X_{B}(t)}\right), r<p \\
\overrightarrow{v_{c}} \cdot \overrightarrow{X(t)}, r \geq p
\end{array}\right\}
$$

where lower bound LB is 0 and upper bound UB is 1 .

\subsection{Step: 3 grabble food}

The value of $\overrightarrow{v b}$ is given by the (4) and reaches to zero by increasing the iteration and $\mathrm{V}_{\mathrm{c}}$ also having lower bound -1 and upper bound 1 and gradually comes to zero.

\section{DESIGN OF CONTROLLERS}

The PID controller is a reliable and simple controller that can deliver good control results. The proportional gain $(\mathrm{Kp})$, integral gain $\left(\mathrm{K}_{\mathrm{I}}\right)$, and derivative gain $\left(\mathrm{K}_{\mathrm{G}}\right)$ are the three primary parameters that must be determined while designing a PID controller. The integral square error (ISE) criterion is used as the objective function in this work for the paper.

$$
J=I S E=\int_{0}^{t_{\operatorname{sim}}}\left(\Delta f_{1}\right)^{2}+\left(\Delta f_{2}\right)^{2}+\left(\Delta P_{T i e}\right)^{2} \cdot d t
$$

For each controller the minimum value will be considered as -2 and maximum value will be considered as 2 .

\section{RESULTS AND DISCUSSION}

In this paper, two area deregulated multi-source power systems to determine the efficiency of the proposed PID controller. It also includes the effects of non-linear factors such as GRC and GDB. The main reason for the inclusion of GRC is that sudden changes in power attract steam to the turbine, which leads to condensation of steam due to diabetic expansion or contraction. The return steam produces small droplets of water that corrode the turbine blades in the event of a collision. This is a long-term process that can lead to serious problems. The GRC limit was set at $0.05 \%$. Similarly, GDB is defined as the sum of speed changes without changing the position of the steam valve. The GDB limit is set at $0.06 \%$. Various simulation studies are carried out to study the efficacy of LFC will be performed. The objective function is utilized to reduce LFC problems by using SMA, and then the performance of SMA-based PI, PID controllers is compared to GWO-based PI and PID controllers. The analysis of performance is done with reference to the percentage peak overshoot and settling time. The simulation results are carried out in different power transactions is being as.

\subsection{Case 1: Pool CO-based transaction}

A pool co-based transaction occurs when DISCOs share a load with any of the GENCOs in the same region. The area participation factor is 0.5 for four values that are assumed to be equal. Figure 3 (a) shows the deviation of frequency in area-1, Figure 3 (b) shows the deviation of frequency in area-2 and Figure 3 (c) shows the deviation of tie line power by using various SMA based and GWO based controllers. Table 1 shows that SMA based controller gives better results as compared to GWO based controller under pool co based transaction.

$$
A P F=\left[\begin{array}{c}
0.5 \\
0.5 \\
0.5 \\
0.5
\end{array}\right] \text { Disco }=\left[\begin{array}{c}
0.1 \\
0.1 \\
0 \\
0
\end{array}\right] \text { p.u DPM }=\left[\begin{array}{llll}
0.5 & 0.5 & 0 & 0 \\
0.5 & 0.5 & 0 & 0 \\
0 & 0 & 0 & 0 \\
0 & 0 & 0 & 0
\end{array}\right]
$$




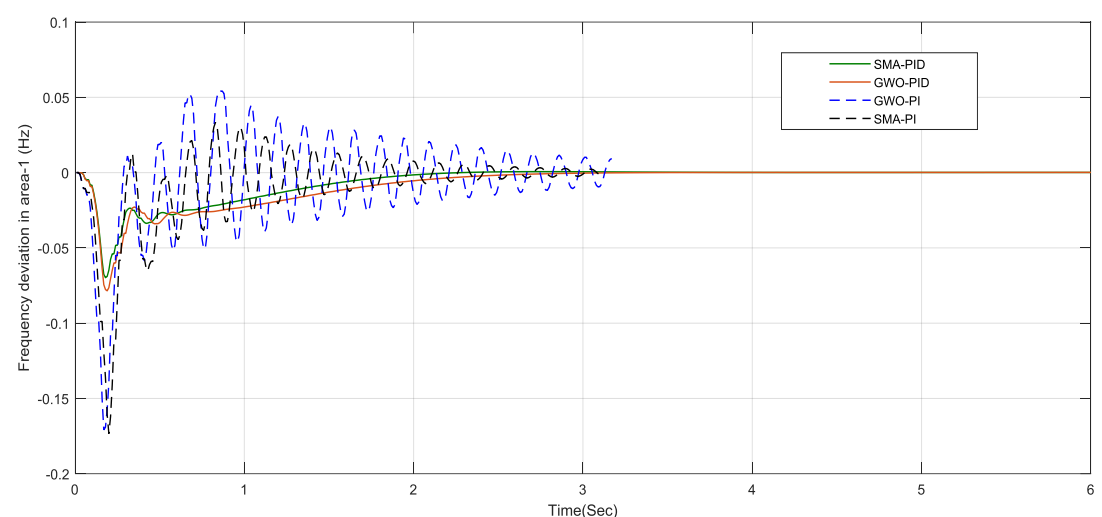

(a)

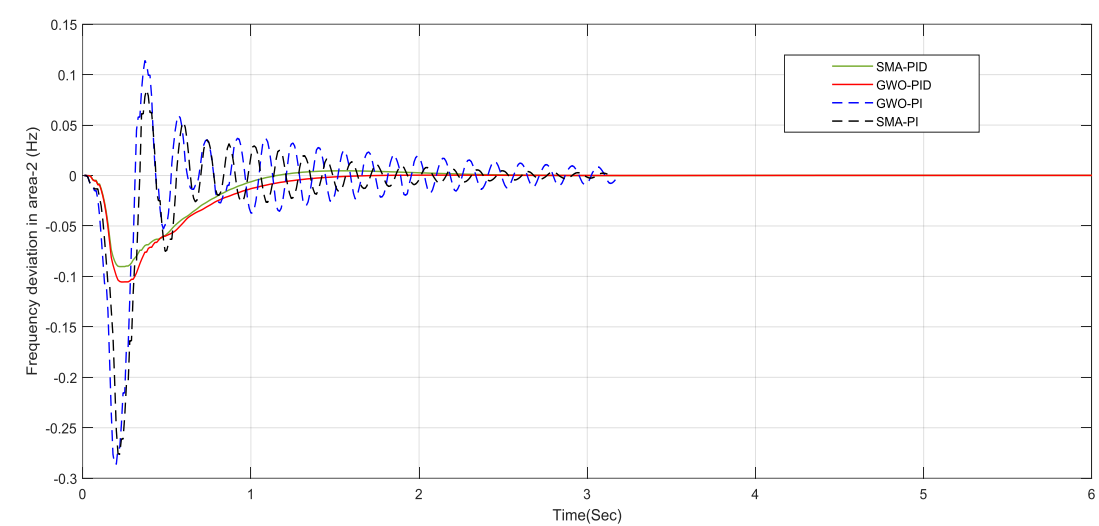

(b)

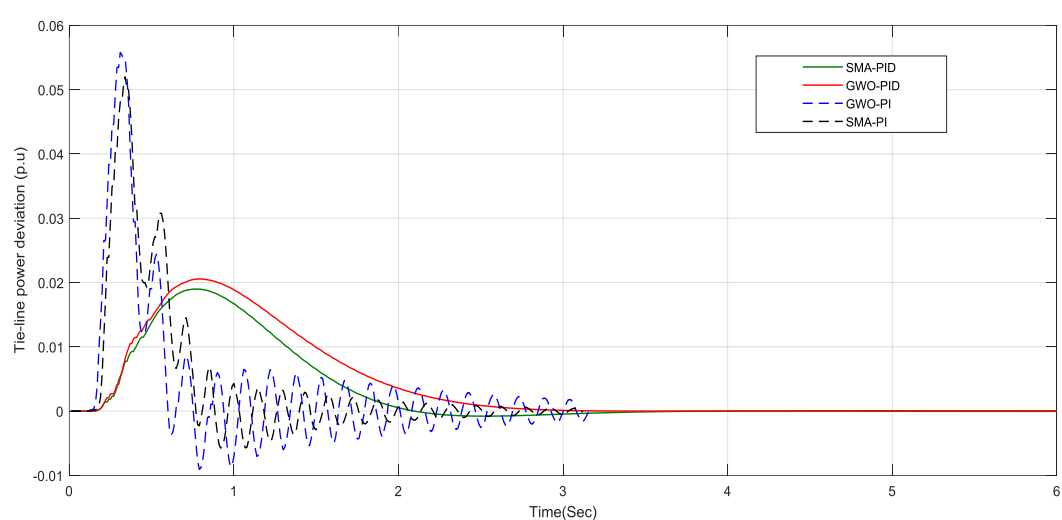

(c)

Figure 3. These figures are; (a) deviation of frequency in area-1, (b) deviation of frequency in area-2, (c) deviation of tie-line power under pool-co based transaction for $1 \%$ step load disturbance

Table 1. Comparison of peak overshoot, undershoot, and settling time using various controllers under pool-CO based transcation

\begin{tabular}{llllllllll}
\hline S. No & \multicolumn{10}{c}{$\%$ Peak overshoot (p.u) } & \multicolumn{2}{c}{ \% Peak undershoot (p.u) } & \multicolumn{3}{c}{ Settling time (Sec) } \\
& $\Delta \mathrm{f}_{1}$ & $\Delta \mathrm{f}_{2}$ & $\Delta \mathrm{P}_{\text {tie }}$ & $\Delta \mathrm{f}_{1}$ & $\Delta \mathrm{f}_{2}$ & $\Delta \mathrm{P}_{\text {tie }}$ & $\Delta \mathrm{f}_{1}$ & $\Delta \mathrm{f}_{2}$ & $\Delta \mathrm{P}_{\text {tie }}$ \\
\hline GWO-PI & 0.05 & 0.12 & 0.055 & 0.18 & 0.28 & 0.01 & 3.5 & 3.2 & 3.6 \\
SMA-PI & 0.04 & 0.08 & 0.053 & 0.16 & 0.26 & 0.009 & 3 & 3 & 3.2 \\
GWO-PID & - & - & 0.02 & 0.08 & 0.11 & - & 2.5 & 1.8 & 2.8 \\
SMA-PID & - & - & 0.018 & 0.06 & 0.09 & - & 1.8 & 1.1 & 2 \\
\hline
\end{tabular}




\subsection{Case 2: Bilateral-based transaction}

Bilateral based transactions occur when DISCOs share the load with any of the GENCOs in another location. The area participation factor is $0.75,0.25,0.5$, and 0.5 for four values that are considered to be uneven. Figure 4 (a) shows the deviation of frequency in area-1, Figure 4 (b) shows the deviation of frequency in area-2 and Figure 4 (c) shows the deviation of tie line power by using various SMA based and GWO based controllers. Table 2 shows that SMA based controller gives better results as compared to GWO based controller under bilateral based transaction.

$$
A P F=\left[\begin{array}{c}
0.75 \\
0.25 \\
0.5 \\
0.5
\end{array}\right] \text { Disco }=\left[\begin{array}{l}
0.1 \\
0.1 \\
0.1 \\
0.1
\end{array}\right] \text { p.u DPM }=\left[\begin{array}{cccc}
0.5 & 0.25 & 0 & 0.3 \\
0.2 & 0.25 & 0 & 0 \\
0 & 0.25 & 1 & 0.7 \\
0.3 & 0.25 & 0 & 0
\end{array}\right]
$$

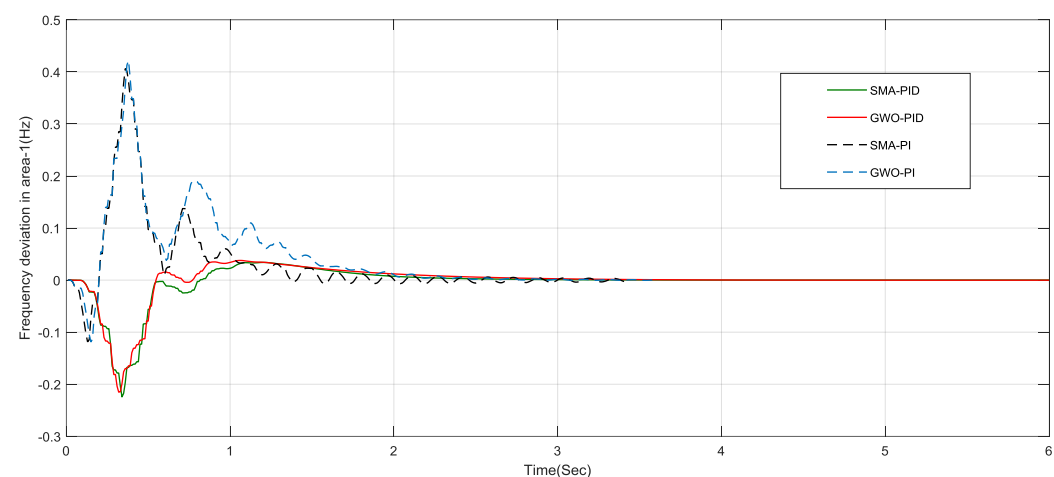

(a)

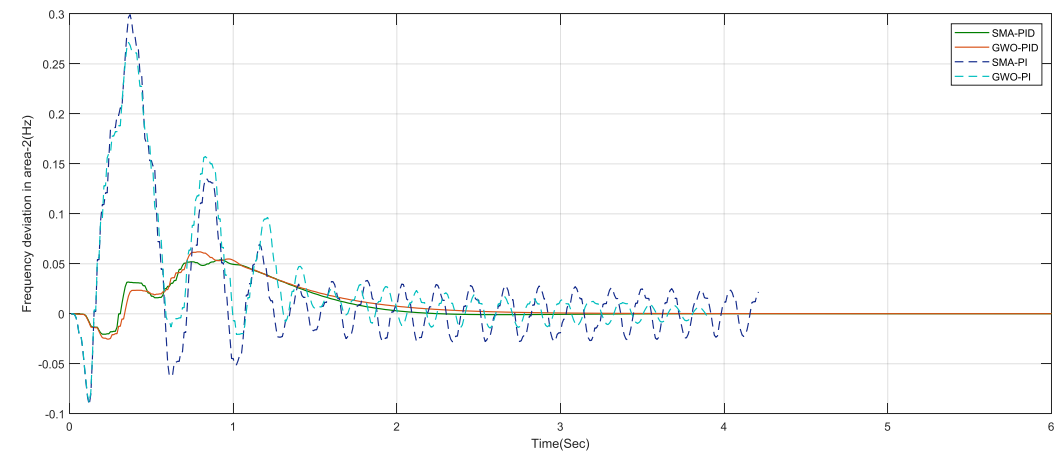

(b)

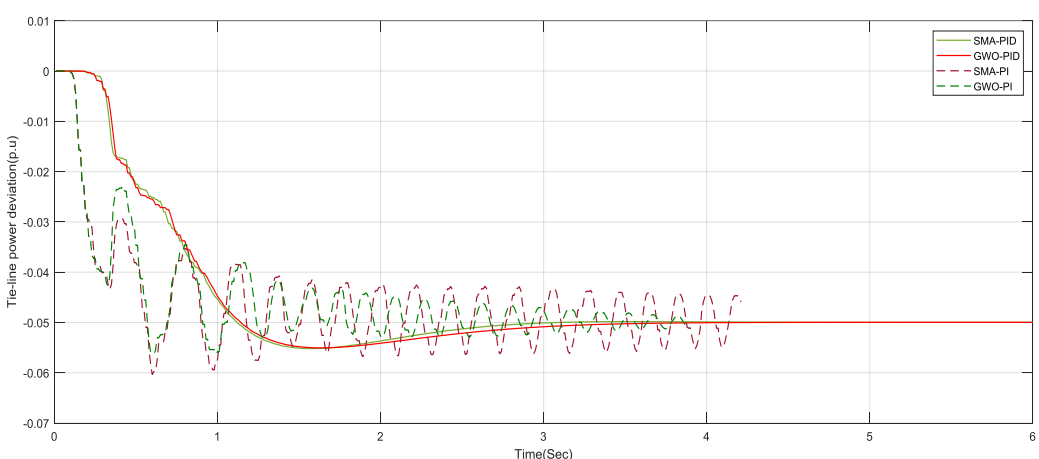

(c)

Figure 4. These figures are; (a) deviation of frequency in area-1, (b) deviation of frequency in area-2, (c) deviation of tie-line power under bilateral based transaction for 1\% step load disturbance 
Table 2. Comparison of peak overshoot, undershoot, and settling time using various controllers for bilateral based transcation

\begin{tabular}{|c|c|c|c|c|c|c|c|c|c|}
\hline \multirow[t]{2}{*}{ S. No } & \multicolumn{3}{|c|}{ \% Peak overshoot (p.u) } & \multicolumn{3}{|c|}{$\%$ Peak undershoot (p.u) } & \multicolumn{3}{|c|}{ Settling time (Sec) } \\
\hline & $\Delta \mathrm{f}_{1}$ & $\Delta \mathrm{f}_{2}$ & $\Delta \mathrm{P}_{\mathrm{tie}}$ & $\Delta \mathrm{f}_{1}$ & $\Delta \mathrm{f}_{2}$ & $\Delta \mathrm{P}_{\text {tie }}$ & $\Delta \mathrm{f}_{1}$ & $\Delta \mathrm{f}_{2}$ & $\Delta \mathrm{P}_{\text {tie }}$ \\
\hline GWO-PI & 0.35 & 0.3 & - & 0.15 & 0.09 & 0.06 & 4.2 & 4.2 & 4.2 \\
\hline SMA-PI & 0.33 & 0.26 & - & 0.14 & 0.08 & 0.057 & 3.8 & 3.8 & 3.9 \\
\hline GWO-PID & 0.03 & 0.06 & - & 0.18 & 0.025 & 0.056 & 2.5 & 2.8 & 3.2 \\
\hline SMA-PID & 0.02 & 0.05 & - & 0.16 & 0.02 & 0.055 & 2.2 & 2.1 & 2.3 \\
\hline
\end{tabular}

\subsection{Case 3: Contract violation}

Contract violation occurs when the disco wants more electricity than the actual value, the contract is disrupted. There is no genco contracting out of this surplus electricity. This uncontracted electricity should be provided by a genco in the same area as the disco. Consider case-2, which requires additional power of 0.1 p.u MW to a disco 1. Figure 5 (a) shows the deviation of frequency in area-1, Figure 5 (b) shows the deviation of frequency in area- 2 and Figure 5 (c) shows the deviation of tie line power by using various SMA based and GWO based controllers. Table 3 shows that SMA based controller gives better results as compared to GWO based controller under contract violation based transaction.

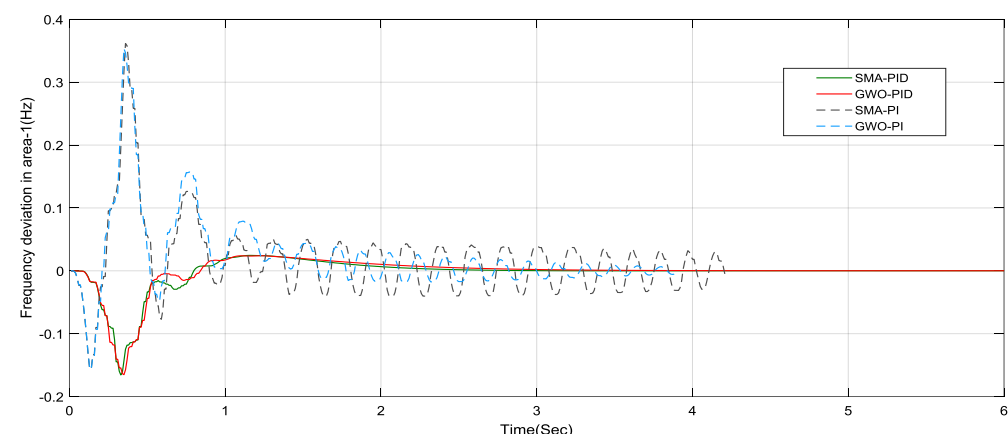

(a)

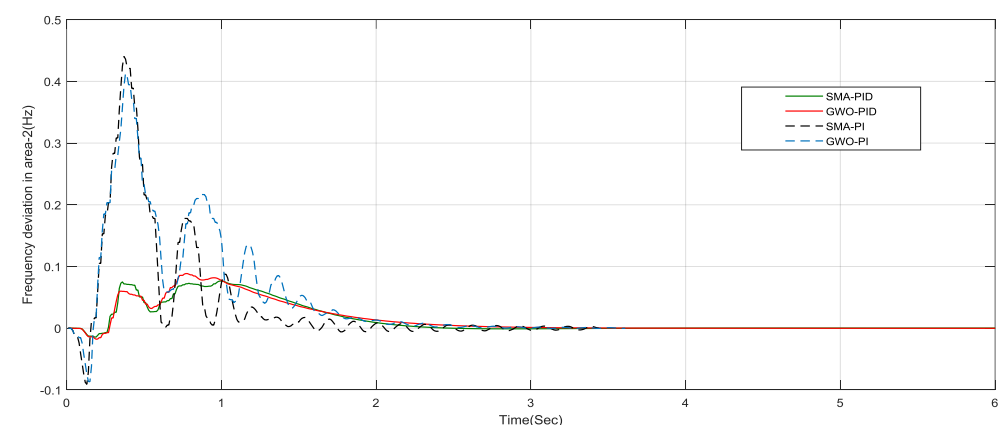

(b)

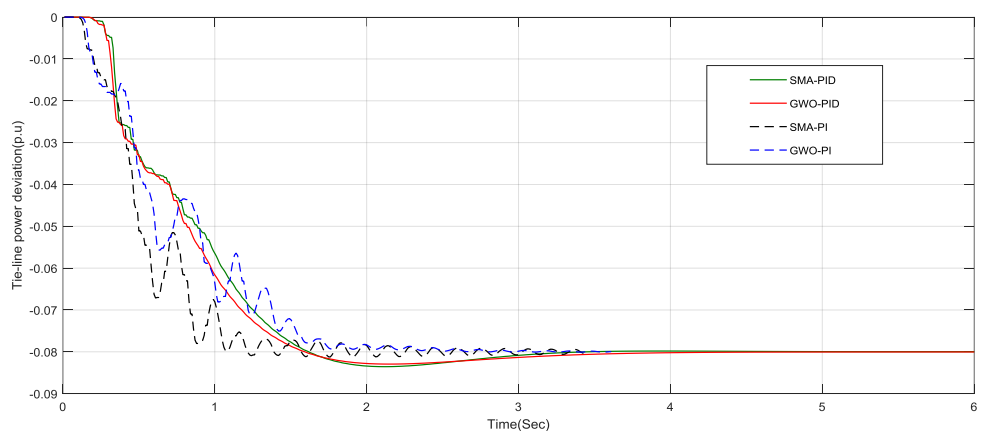

(c)

Figure 5. These figures are; (a) deviation of frequency in area-1,5, (b) deviation of frequency in area- 2; 5, (c) deviation of tie-line power under contract violation for $1 \%$ step load disturbance 
Table 3. Comparison of peak overshoot, undershoot, and settling time using various controllers for contract violation based transcation

\begin{tabular}{lccccccccc}
\hline S. No & \multicolumn{3}{c}{$\%$ Peak overshoot (p.u) } & \multicolumn{3}{c}{$\%$ Peak undershoot (p.u) } & \multicolumn{3}{c}{ Settling time (Sec) } \\
& $\Delta \mathrm{f}_{1}$ & $\Delta \mathrm{f}_{2}$ & $\Delta \mathrm{P}_{\text {tie }}$ & $\Delta \mathrm{f}_{1}$ & $\Delta \mathrm{f}_{2}$ & $\Delta \mathrm{P}_{\text {tie }}$ & $\Delta \mathrm{f}_{1}$ & $\Delta \mathrm{f}_{2}$ & $\Delta \mathrm{P}_{\text {tie }}$ \\
\hline GWO-PI & 0.4 & 0.42 & - & 0.1 & 0.08 & 0.08 & 3.8 & 3.2 & 3.8 \\
SMA-PI & 0.38 & 0.4 & - & 0.08 & 0.07 & 0.08 & 3.2 & 2.8 & 3.6 \\
GWO-PID & - & 0.09 & - & 0.2 & - & 0.082 & 2.2 & 2.5 & 3.3 \\
SMA-PID & - & 0.07 & - & 0.2 & - & 0.082 & 2 & 2.3 & 3.1 \\
\hline
\end{tabular}

\section{CONCLUSION}

This paper examines the performance of a PID controller in deregulated market structure for various transactions and contract violations. In the power system, load demand is a difficult challenge to solve since it requires the design of various optimum controllers. The main task of the controller is to ensure that the frequency is maintained and the voltage magnitude is constant at all times. The DPM approach is implemented. A comparison of the two controllers reveals that the SMA based PI, PID controller outperforms the GWO based PI, PID controller in terms of settling time, overshoot, and undershoot.

\section{REFERENCES}

[1] W. Tan, "Unified Tuning of PID Load Frequency Controller for Power Systems via IMC," in IEEE Transactions on Power Systems, vol. 25, no. 1, pp. 341-350, Feb. 2010, doi: 10.1109/TPWRS.2009.2036463.

[2] K. P. S. Parmar, S. Majhi, and D. P. Kothari, "Automatic generation control of an interconnected hydrothermal power system,” 2010 Annual IEEE India Conference (INDICON), 2010, pp. 1-5, doi: 10.1109/INDCON.2010.5712663.

[3] K. Das, P. Das, and S. Sharma, "Load frequency control using classical controller in an isolated single area and two area reheat thermal power system," International Journal of Emerging Technology and Advanced Engineering, vol. 2, no. 3, pp. 403-409, March 2012, doi: 10.1.1.413.5255.

[4] S. Saxena and Y. V. Hote, "Load Frequency Control in Power Systems via Internal Model Control Scheme and Model-Order Reduction," in IEEE Transactions on Power Systems, vol. 28, no. 3, pp. 2749-2757, Aug. 2013, doi: 10.1109/TPWRS.2013.2245349.

[5] G. T. C. Sekhar, R. K. Sahu, A. K. Baliarsingh, and S. Panda, "Load frequency control of power system under deregulated environment using optimal firefly algorithm," Int. J. Elect. Power Energy Syst., vol. 74, pp. 195-211, January 2016, doi: 10.1016/j.ijepes.2015.07.025.

[6] K. P. S. Parmar, S. Majhi, and D. P. Kothari, "LFC of an interconnected power system with multi-source power generation in deregulated power environment," Int. J. Elect. Power Energy Syst., vol. 57, pp. 277-286, May 2014, doi: 10.1016/j.ijepes.2013.11.058.

[7] R. J. Abraham, D. Das, and A. Patra, "Load following in a bilateral market with local controllers," Electr. Power Energy Syst., vol. 33, no. 10, pp. 1648-1657, December 2011, doi: 10.1016/j.ijepes.2011.06.033.

[8] P. Bhatt, R. Roy, and S. P. Ghoshal, "Optimized multi area AGC simulation in restructured power systems," Electr.Power Energy Syst., vol. 32, no. 4, pp. 311-322, May 2010, doi: 10.1016/j.ijepes.2009.09.002.

[9] W. Tan, H. Zhang, and M. Yu, "Decentralized load frequency control in deregulated environments," Electrical Power and Energy Systems, vol. 41, no. 1, pp. 16-26, October 2012, doi: 10.1016/j.ijepes.2012.02.013.

[10] H. Guolian, Q. Lina, Z. Xinyan, and Z. Jianhua, "Application of PSO-based fuzzy PI controller in multi-area AGC system after deregulation," 2012 7th IEEE Conference on Industrial Electronics and Applications (ICIEA), 2012, pp. 1417-1422, doi: 10.1109/ICIEA.2012.6360946.

[11] G. T. Chandra Sekhar, R. K. Sahu, A. K. Baliarsingh, and Sidhartha Panda, "Load frequency control of power system under deregulated environment using optimal firefly algorithm,” Int. J. Electr. Power Energy Syst., vol.74, pp.195-211, 2016, doi: 10.1016/j.ijepes.2015.07.025.

[12] L. C. Saikia, J. Nanda, and S. Mishra, "Performance comparison of several classical controllers in AGC for multiarea interconnected thermal system," International Journal of Electrical Power \& Energy Systems, vol. 33, no. 3, pp. 394-401, March 2011, doi: 10.1016/j.ijepes.2010.08.036.

[13] B. K. Sahu, T. K. Pati, J. R. Nayak, S. Panda, and S. K. Kar, "A novel hybrid LUS-TLBO optimized fuzzy-PID controller for load frequency control of multi-source power system," Int. J. Electr. Power Energy Syst., vol. 74, pp. 58-69, January 2016, doi: 10.1016/j.ijepes.2015.07.020.

[14] A. Huddar and P. S. Kulkarni, "A robust method of tuning a decentralized proportional-integral load frequency controller in a deregulated environment using genetic algorithms," Electric Power Components and Systems, vol. 37, no. 3, pp. 265-286, February 2009, doi: 10.1080/15325000802454419.

[15] M. Shiroei and A. M. Ranjbar, "Supervisory predictive control of power system load frequency control," Int. J. Electr. Power Energy Syst., vol. 61, pp. 70-80, Oct. 2014, doi: 10.1016/j.ijepes.2014.03.020.

[16] Md N. Anwar and S. Pan, "A new PID load frequency controller design method in frequency domain through direct synthesis approach,” Int. J. Elect. Power Energy Syst., vol. 67, pp. 560-569, May 2015, doi: 10.1016/j.ijepes.2014.12.024.

[17] J. Morsali, K. Zare, and M. T. Hagh, "AGC of interconnected multi-source power system with considering GDB and GRC nonlinearity effects," 2016 6th Conference on Thermal Power Plants, 2016, pp. 12-17, doi: 10.1109/CTPP.2016.7482927. 
[18] R. Ramjug-Ballgobin, S. Z. S. Hassen, and S. Veerapen, "Load frequency control of a nonlinear two-area power system," 2015 International Conference on Computing, Communication and Security (ICCCS), 2015, pp. 1-6, doi: 10.1109/CCCS.2015.7374172.

[19] Tain-Sou Tsay, "Load-frequency control of interconnected power system with governor backlash nonlinearities," Electrical Power and Energy Systems, vol. 33, no. 9, pp. 1542-1549, Nov. 2011, doi: 10.1016/j.ijepes.2011.06.005.

[20] E. S. Ali and S. M. Abd-Elazim, "Bfoa based design of pid controller for two area load frequency control with nonlinearities," International Journal of Electrical Power \& Energy Systems, vol. 51, pp. 224-231, 2013, doi: 10.1016/j.ijepes.2013.02.030.

[21] S. Rupatharani and S. Selvakumari, "Load Frequency Control of Multi-Area Power Systems using Genetic Algorithm," International Journal of Engineering Research \& Technology, vol. 3, no. 16, 2015.

[22] H. Gozde and M. C. Taplamacioglu, "Automatic generation control application with craziness based particle swarm optimization in a thermal power system," Electrical Power and Energy Systems, vol. 33, no. 1, pp. 8-16, January 2011, doi: 10.1016/j.ijepes.2010.08.010.

[23] E. S. Ali and S. M. Abd-Elazim, "Bacteria foraging optimization algorithm based load frequency controller for interconnected power system," Electrical Power and Energy Systems, vol. 33, no. 3, pp. 633-638, 2011, doi: 10.1016/j.ijepes.2010.12.022.

[24] S. Prakash and S. K. Sinha, "Application of artificial intelligence in load frequency control of interconnected power system," International Journal of Engineering, Science and Technology, vol. 3, no. 4, pp. 264-275, 2011, doi: 10.4314/ijest.v3i4.68558.

[25] S. Deb, S. Fong, and Z. Tian, "Elephant Search Algorithm for optimization problems," 2015 Tenth International Conference on Digital Information Management (ICDIM), 2015, pp. 249-255, doi: 10.1109/ICDIM.2015.7381893.

[26] D. K. Sambariya and S. Shrangi, "Optimal design of pid controller for load frequency control using harmony Search algorithm," Indonesian Journal of Electrical Engineering and Computer Science, vol. 5, no. 1, pp. 19-32, January 2017, doi: 10.11591/ijeecs.v5.i1.pp19-32.

[27] D. Guha, P. K. Roy, and S. Banerjee, "Load frequency control of large scale power system using quasi-oppositional grey wolf optimization Algorithm," Engineering Science and Technology, an International Journal, vol. 19, no. 4, pp. 1693-1713, December 2016, doi: 10.1016/j.jestch.2016.07.004. 